\title{
EFFECT OF INTERACTION BETWEEN FUROSEMIDE AND OXYTERCYCLINE ON BLOOD UREA AND CREATININE IN RATS
}

\author{
By \\ Abd El - Hamid, M. A.
}

From

The Department of Pharmacology, Faculty of Medicine, Mansoura University.

Received for Puplication 2/10/1988

\section{INTRODUCTION}

Recently Seegers et al, (1979) reported that concurrent administration of paracetamol with aspirin resulted in decreased gastric acidity indueed by aspirin in rats, this effect is due to stimulation of endogenous production of prostaglandins produced by paracetamol. The work of Seegers et al. (1979) was based on the observations of Bobak et al. (1978) and Mc Donald et al., (1979) that paracetamol could stimulate the prostaglindin sythetase of bovine seminal vesicles in vitro.

The antagonism of paractamol to the gastric hyperacidity, may be accompanied by an antagonism to the therapeutic efficacy of aspirin but, on the other hand, paracetamol has pharmacological properties which are similar to those of aspirin and might thereforefore augment the therapeutic efficacy. In the present work the inter- action between paracetamol and aspirin with regard to their analgesic and anti anflammatory activities were studied in rats.

\section{MATERIAL AND METHODS}

\section{Drugs Used :}

Paracetamol (Abimol tablet - $A B I$ ) and aspirin tablet - Bayer) were suspended in 4\% Tween - 20 and administered orally by using gastric tube. The dosages of both paracetamol and aspirin were $250 \mathrm{mg} / \mathrm{Kg}$, because Seegers et al., (1979) found that this dose of aspirin Produced considerable gastric damage that was reduced significantly by the same dose of paracetamol.

\section{Animals Used :}

80 albino rats of both sex weighing $100-200 \mathrm{gm}$ were used in the MANSOURA MEDICAL JOURNAL 


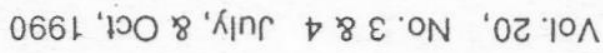

u!puej6ełsodd 6u!̣npad Kq '(9L6 " "ןe 1ә !rsueqos) səp!xodəd p!d!! sno!̣xou

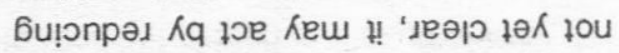

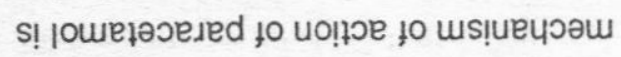

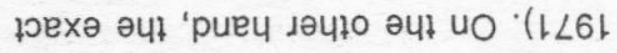
'әue $\wedge$ ) su!pueןbełsodd bu!̣e!̣pom uo!!

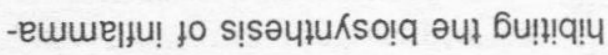

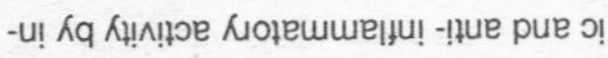
-sə6|eue sı! suәxә Kiqeqoud u!!!ds $\forall$

uo!̣oe to әрош

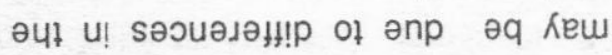

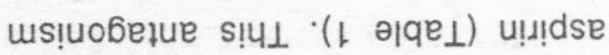

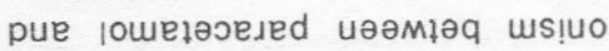

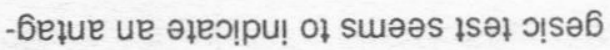

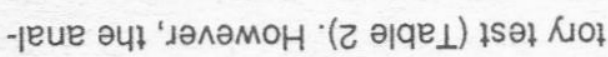

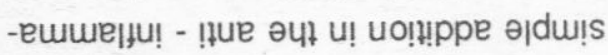

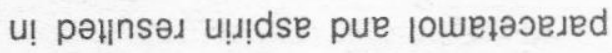

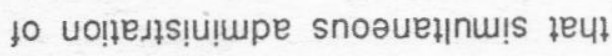

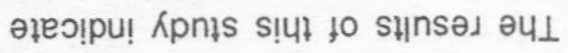

\section{NoIsSnOSIa}

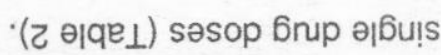

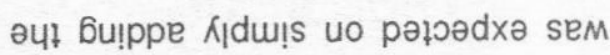

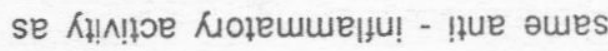

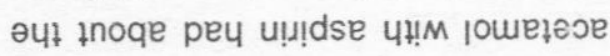

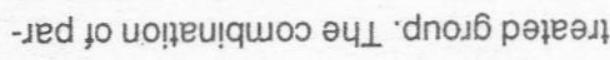

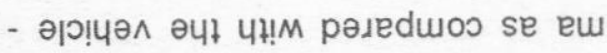
-әрәо med pәonpu! - u!̣әәә6енео әцा

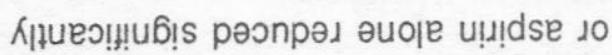

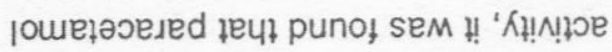

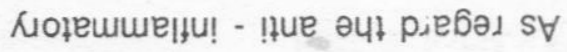

-(us!̣obęue) s6rnp

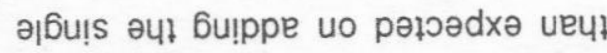

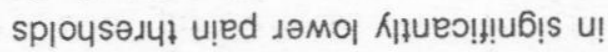

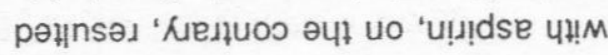

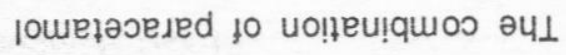
-dnod6 jonuos

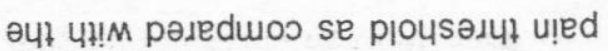

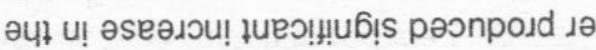

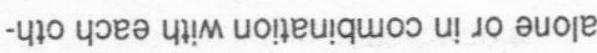
s6nגp чloq łецł smous ( 1 ) әवе $\perp$

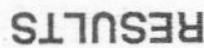

sônup

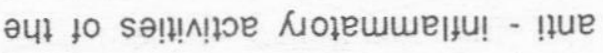

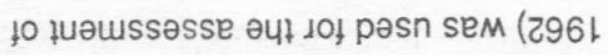

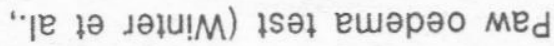

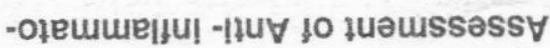
: КП!ก!rว Ka

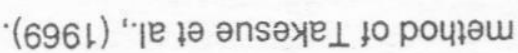

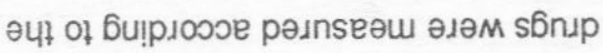

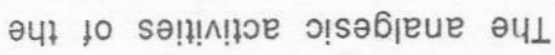

: Кมกเฺ็

ग!səดןอu to tuamssess

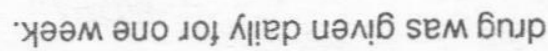

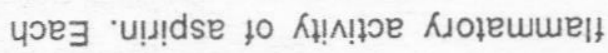

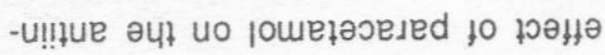

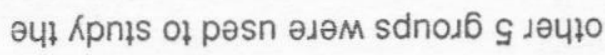

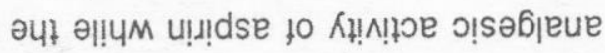

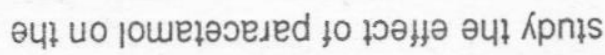

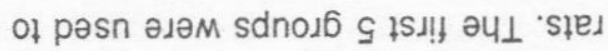
8 to słs!suos dnoj6 чәеә sdnod6 or

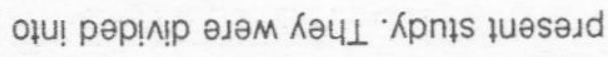


endoperoxides (Kuehl et al., 1977), or by indirectly blocking prostaglandin synthesis (Lands, 1981).

Perhaps paracetamol affects the inflammatory reaction in the same way as asprine, but influences the pain reaction in such a way that it antagonizes the analgesic effect of aspirin.

This antagonism is not too serious for a possible clinical application of the combination, as the analgesic activity of aspirin, which is antagonized by paracetamol, is less important than its anti - inflammatory action when aspirin is used in treatment of inflammatory diseases. Moreover, the combination of aspirin with paracetamol resulted in analgesic effects which were not substantially lower than those of the single drugs.

As mentioned above the anti - inflammatory effect of aspirin and paracetamol add to each other. Considering this and the protection which paracetamol may offer against gastric damage produced by aspirin (Seegers et al., 1979) a combination of these drugs imght be of value in analgesic anti - rheumatic therapy.

\section{SUMMARY AND CONCLUSION}

Since some workers reported that paracetamol can antagonize the toxic effect of aspirin on the gastric acidity in rats, the present work was done to study the effect of paracetamol on the analgesic and anti - inflammatory activity of aspirin in rats. It was found that the anti - inflammatory effect of paracetamol and aspirin additive. Although antagonism was observed in the analgesic test, the effect of the combination was not inferior to that of paracetamol alone.

In light of the present study and reports of other workers on experimental animals, it may be concluded that although paracetamol antagonized the analgesic effect of aspirin, yet the protection which paracetamol offer against gastric damage produced by aspirin make the combination of both drugs mightbe of value in antirheumatic therapy. 


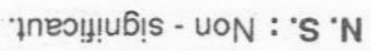

s6nup

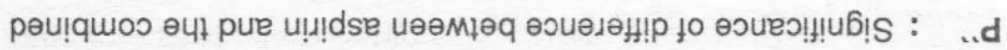
s6nup persel

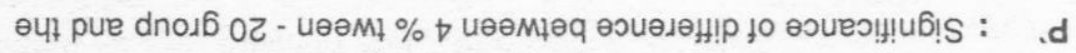
dnod6

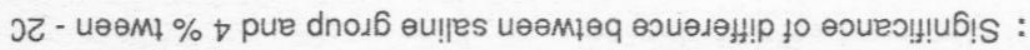

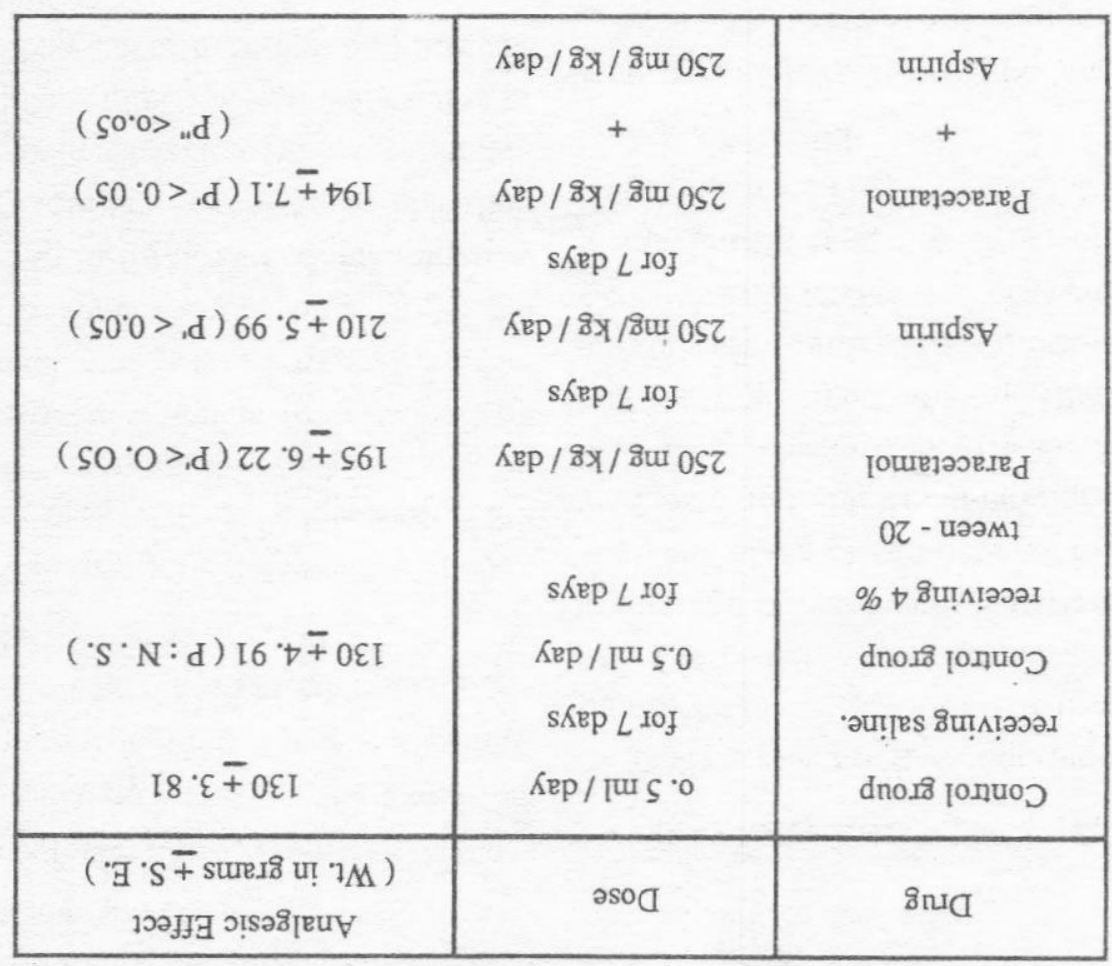

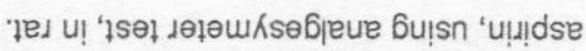

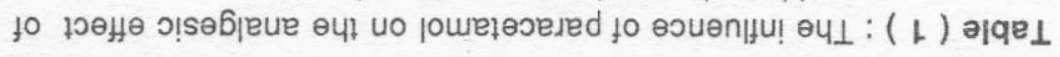


Table (2): The influence of paracetamol on the antiinflammatory effect of aspirin, using paw oedema test, in rats.

\begin{tabular}{|c|c|c|}
\hline Drug & Dose & $\begin{array}{c}\text { Anti-inflammatory effects } \\
\text { (Thickness of paw in cm. } \\
\pm \text { S. E. }) .\end{array}$ \\
\hline $\begin{array}{c}\text { Control group } \\
\text { receiving saline. } \\
\text { Control group } \\
\text { receiving } \\
\text { tween }-20\end{array}$ & $0.5 \mathrm{ml} /$ day & $3.9 \pm 0.12$ \\
$\begin{array}{c}\text { Paracetamol } \\
\vdots\end{array}$ & $250 \mathrm{mg} / \mathrm{kg} /$ day \\
Aspirin. & $250 \mathrm{mg} / \mathrm{kg} /$ day & $3.1 \pm 0.03\left(\mathrm{P}^{\prime}<0.05\right)$ \\
Paracetamol & $250 \mathrm{mg} / \mathrm{kg} /$ day $)$ \\
+ & + & $2.2 \pm 0.073\left(\mathrm{P}^{\prime}<0.05\right)$ \\
Aspirin & $250 \mathrm{mg} / \mathrm{kg} /$ day & $\left(\mathrm{P}^{\prime \prime}<0.05\right)$ \\
\hline
\end{tabular}

All drugs were given orally for 7 days.

P : Significance of difference between saline group and $4 \%$ tween - 20 group.

P. : Significance of difference between $4 \%$ tween - 20 group and the tested drugs.

P' : Significance of difference between aspirin and combined drugs. 


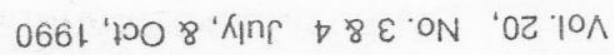

t十S: 1161

pow lo!g d dx . oos rodg

: (2961) $\cdot M \cdot v$ 'ssnN

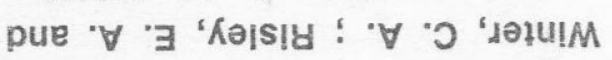

$$
\text { ¿८ट: เฉ乙 }
$$

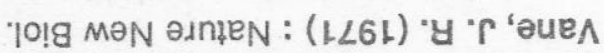

'88L

$: 12$ josemiend masend

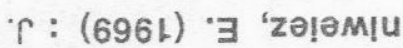

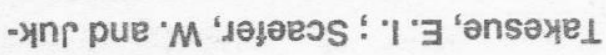

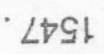

: se pow jo!g eto

: (9L6L) r ' $\mathrm{c}$ 'nzew pue ' $\mathrm{g}$ 'oqeo

$$
0 \nmid 8: 1 \varepsilon
$$

- jovemieyd r $r:(626 \mathrm{~L})$
. $x$ 'yl!mpioon uen

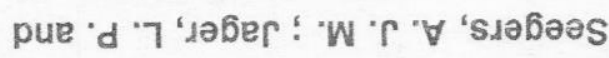

\section{$16 \varepsilon$}

:2L looemsend 'maцวo!g

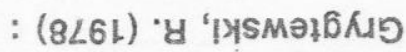

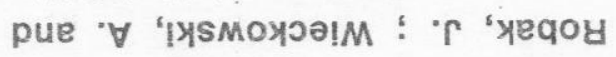

- L6t:89 jooemseyd $r$

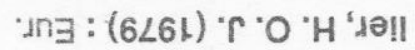

-joכ pue $r$ ' $M$ 'uosqio - pleuod ow

- 8L: : $\cdot$. IOS joormeyd

spuəd1: (186L) 'W $\exists$ 'M 'spue

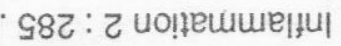

: (LL6L) $M \cdot d \cdot d$ 'ue6 $\exists$ pue

כ" כ"

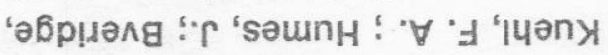

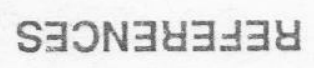

